\title{
AN ALGORITHM FOR ESTIMATING THE PLUME CENTERLINE TEMPERATURE AND CEILING JET TEMPERATURE IN THE PRESENCE OF A HOT UPPER LAYER
}

William D. Davis \& Kathy A. Notarianni Building and Fire Research Laboratory

Gaithersburg, Maryland 20899

Phillip Z. Tapper

Goddard Space Flight Center

Greenbelt, Maryland 20771

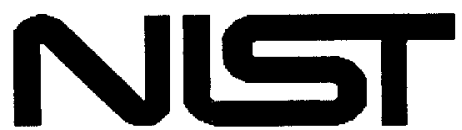

United States Department of Commerce Technology Administration

National Institute of Standards and Technology 


\section{AN ALGORITHM FOR ESTIMATING THE PLUME CENTERLINE TEMPERATURE AND CEILING JET TEMPERATURE IN THE PRESENCE OF A HOT UPPER LAYER}

William D. Davis \& Kathy A. Notarianni Building and Fire Research Laboratory National Institute of Standards and Technology Gaithersburg, Maryland 20899

Phillip Z. Tapper

Goddard Space Flight Center

National Aeronautics and Space Administration

Greenbelt, Maryland 20771

June 1998

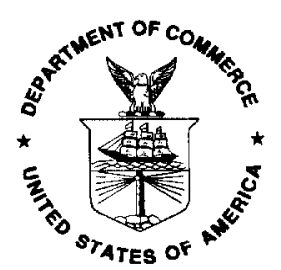

\section{U.S. Department of Commerce}

William M. Daley, Secretary

Technology Administration

Gary R. Bachula, Under Secretary for Technology

National Institute of Standards and Technology

Raymond G. Kammer, Director 


\section{TABLE OF CONTENTS}

ACKNOWLEDGMENTS $\ldots \ldots \ldots \ldots \ldots \ldots \ldots \ldots \ldots \ldots \ldots \ldots \ldots \ldots \ldots \ldots$

INTRODUCTION $\ldots \ldots \ldots \ldots \ldots \ldots \ldots \ldots \ldots \ldots \ldots \ldots \ldots \ldots \ldots \ldots \ldots$

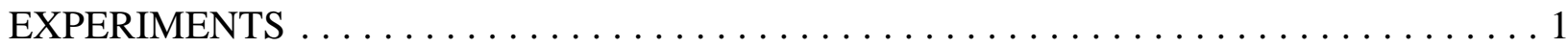

PLUME CENTERLINE TEMPERATURE $\ldots \ldots \ldots \ldots \ldots \ldots \ldots \ldots \ldots \ldots \ldots \ldots \ldots \ldots 4$

RADIATIVE FRACTION $\ldots \ldots \ldots \ldots \ldots \ldots \ldots \ldots \ldots \ldots \ldots \ldots \ldots \ldots \ldots$

PLUME CENTERLINE TEMPERATURE COMPARISONS $\ldots \ldots \ldots \ldots \ldots \ldots \ldots \ldots \ldots .7$

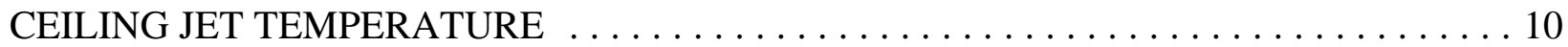

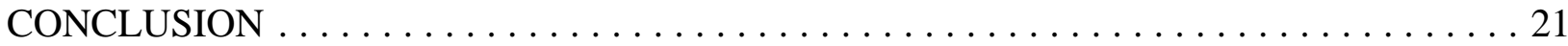

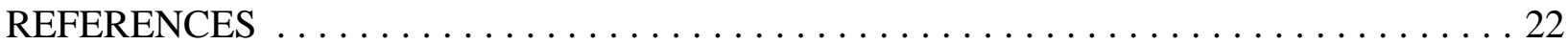




\section{ACKNOWLEDGMENTS}

We gratefully acknowledge the support of the National Aeronautics and Space Administration for their support of this project. Their support over the past three years has led to a substantial improvement in the capability of computer fire models to model detector performance in high bay structures.

We would also like to thank the Naval Facilities Engineering Command, especially Joseph E. Gott, for the use of the high bay data prior to publication. 


\title{
An Algorithm for Calculating the Plume Centerline Temperature and Ceiling Jet Temperature in the Presence of a Hot Upper Layer
}

\author{
William D. Davis \& Kathy A. Notarianni \\ National Institute of Standards and Technology \\ Phillip Z. Tapper \\ National Aeronautics and Space Administration
}

\section{INTRODUCTION}

Recent experiments conducted in hangars with ceiling heights of $15 \mathrm{~m}$ and $22 \mathrm{~m}$ provided a test bed for computer model comparisons with ceiling jet temperatures, plume centerline temperatures, and predictions of detector activations [1]. A comparison of the models in DETACT-QS [2] and FPEtool version 3.2 [3] with the experimental data indicated that the predictive capabilities of the models were not in agreement with the experimental results when hot upper layers were present. This observation has led to the development of improved models to predict plume centerline temperatures and ceiling jet temperatures. The shape of the ceiling jet temperature beneath the ceiling as predicted using LAVENT version 1.2 [4] has been compared to the data for experiments with and without draft curtains. It is shown that the ceiling jet temperature profile changes significantly when a hot layer develops.

The experiments were designed to provide insight into the behavior of jet fuel fires in aircraft hangars and to study the impact of these fires on the design and operation of a variety of fire protection systems. As a result, the test series included small fires designed to investigate the operation of UV/IR detectors and smoke detectors as well as large fires which were used to investigate the operation of ceiling mounted heat detectors and sprinklers. The impact of the presence or absence of draft curtains was also studied in the $15 \mathrm{~m}$ hangar.

It is shown that in order to predict the plume centerline temperature within experimental uncertainty, the entrainment of the upper layer gas must be modeled. For large fires, the impact of a changing radiation fraction must also be included in the calculation. The dependence of the radial temperature profile of the ceiling jet as a function of layer development is demonstrated and a ceiling jet temperature algorithm which includes the impact of a growing layer is developed.

\section{EXPERIMENTS}

Two experimental sites were used to conduct the hangar experiments. The first site was a warm temperature site $\left(\sim 30^{\circ} \mathrm{C}\right)$ at Barbers Point, Hawaii and the second site was a cool temperature site $\left(\sim 12{ }^{\circ} \mathrm{C}\right)$ at Keflavik, Iceland. At the Barbers Point site, a total of eleven fire experiments were conducted. Six of the experiments included a draft curtain $3.7 \mathrm{~m}$ deep which enclosed an area of dimensions $18.3 \mathrm{~m} \times 24.4 \mathrm{~m}$. The hangar measured $97.8 \mathrm{~m} \times 73.8 \mathrm{~m}$ in area and had a ceiling height at the center of $15.1 \mathrm{~m}$. The ceiling height at the center of the draft curtained area 
was $14.9 \mathrm{~m}$. As an aid in describing the experimental set up, the directions east and west will be used to describe directions pointing parallel to the $24.4 \mathrm{~m}$ side of the draft curtain while north and south will be used to describe directions perpendicular to the $24.4 \mathrm{~m}$ side. A plan view of the

hangar bay is shown in figure 1.

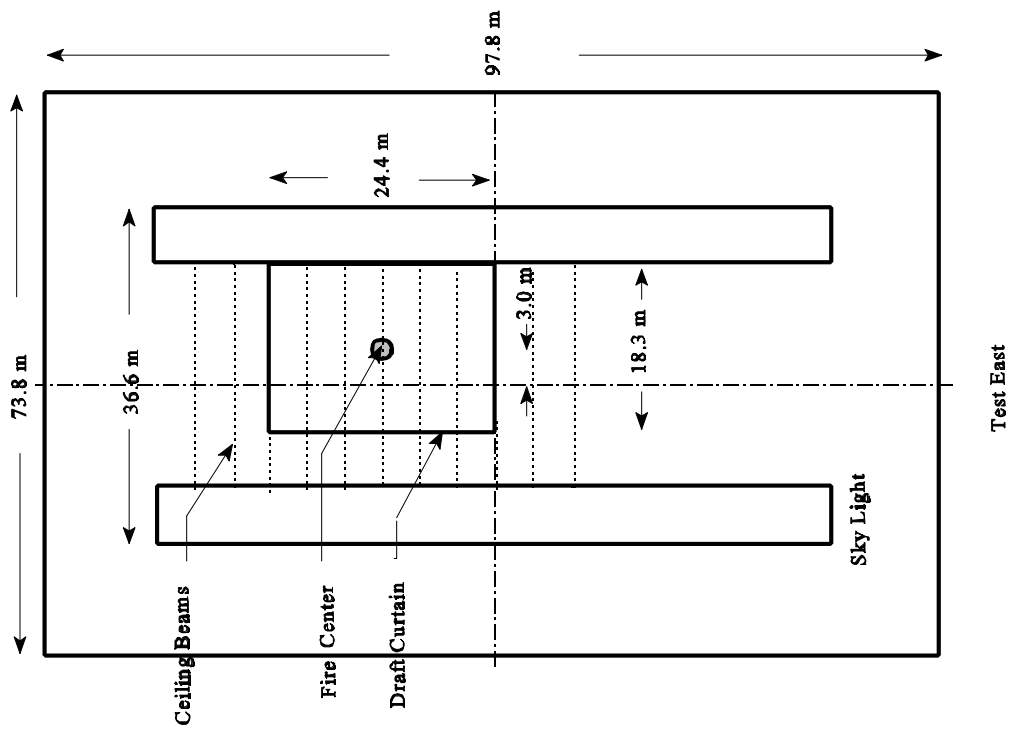

The hangar roof consists of built-up tar and gravel over a corrugated metal deck. The roof slopes from a height of $14.9 \mathrm{~m}$ at the center toward the east and west walls which are $13.4 \mathrm{~m}$ high. The metal deck is directly supported by $0.25 \mathrm{~m}$ I beams which run the $(\mathrm{N}-\mathrm{S})$ width of the hangar and are spaced $4.1 \mathrm{~m}$ on center. The I beams are supported by open steel trusses which run perpendicular to the beams $(\mathrm{E}-\mathrm{W})$ and are spaced $6.1 \mathrm{~m}$ on center. These trusses

Three of the six draft curtain experiments developed sufficiently large excess temperatures at the ceiling to provide a useful test bed for the development of ceiling jet correlations. The experimental fires were $1.5 \mathrm{~m}, 2.0 \mathrm{~m}$, and $2.5 \mathrm{~m}$ diameter JP-5 pan fires which produced steady state heat release rates (HRR) of 2.8 MW, 6.8 MW, and 7.7 MW respectively. Due to a load cell failure, the heat release rate for the $2.5 \mathrm{~m}$ diameter fire was calculated from the average mass loss over the duration of the fire. The average mass loss was determined by measuring the initial and final volume of fuel contained in the pan and multiplying the volume difference by the fuel density to determine the fuel mass consumed by the fire. Estimates of HRR using the average mass loss agreed to within $20 \%$, on average, with the HRR calculated directly from the load cell measurements.

The fire plume in the $6.8 \mathrm{MW}$ experiment developed a fire whirl at two different times during the experiment. The existence of these plume whirls not only impacted the characteristics of the plume temperature but produced distinct changes in the layer temperature time history. As a result, this experiment will not be included in the analysis. 
Two experiments, which did not include draft curtains, developed sufficiently large excess temperatures at the ceiling to be useful in studying the unconfined ceiling jet. These fires were 2.0 $\mathrm{m}$ and $2.5 \mathrm{~m}$ diameter JP-5 pan fires with steady state heat release rates of 5.6 MW and 7.7 MW. The 5.6 MW heat release rate was calculated using the average mass loss over the duration of the fire while the $7.7 \mathrm{MW}$ heat release rate was assumed to be equal to the estimated heat release rate of the $2.5 \mathrm{~m}$ diameter pan fire with draft curtains since average mass loss data was not available for this test.

Thermocouples were used to measure the ceiling jet temperature at radial distances from plume center of $1.5 \mathrm{~m}, 3.0 \mathrm{~m}, 6.1 \mathrm{~m}, 9.1 \mathrm{~m}$, and $11.6 \mathrm{~m}$ in the experimental east and west directions, and at $1.5 \mathrm{~m}, 3.0 \mathrm{~m}, 6.1 \mathrm{~m}$, and $8.5 \mathrm{~m}$ in the experimental north and south directions. The thermocouples were located $0.31 \mathrm{~m}$ beneath the ceiling. The $\mathrm{r} / \mathrm{H}$ value $(\mathrm{r}$ is the radial distance from the plume center and $\mathrm{H}$ is the height of the ceiling above the fire surface) for the $1.5 \mathrm{~m}$ thermocouples is 0.1 which means that these thermocouples are in the plume. All the other thermocouples were located outside the plume region. Four thermocouple trees with thermocouples located at $0.15 \mathrm{~m}, 0.3 \mathrm{~m}, 0.46 \mathrm{~m}, 0.61 \mathrm{~m}$, and $0.76 \mathrm{~m}$ beneath the ceiling were located $6.1 \mathrm{~m}$ from plume center in the north, south, east, and west directions, while a fifth tree with thermocouples located at $0.15 \mathrm{~m}, 0.3 \mathrm{~m}, 0.46 \mathrm{~m}, 0.76 \mathrm{~m}, 1.22 \mathrm{~m}$, and $3.0 \mathrm{~m}$ beneath the ceiling was located at $9.1 \mathrm{~m}$ toward experimental east. These thermocouple trees are used to investigate the temperature dependence of the ceiling jet as a function of distance beneath the ceiling.

A total of 21 pan fire experiments were conducted at Keflavik, Iceland. The Keflavik hangar measured $73.8 \mathrm{~m}$ by $45.7 \mathrm{~m}$ and had a barrel roof which was $22.3 \mathrm{~m}$ high at the center and $12.2 \mathrm{~m}$ high at the walls. Corrugated steel draft curtains were used to divide the ceiling into five equal bays approximately $14.8 \mathrm{~m}$ by $45.7 \mathrm{~m}$ with the fire experiments conducted in the middle bay and centered under the $22.3 \mathrm{~m}$ high ceiling.

The primary roof support consisted of a series of steel trusses which form arches spanning the width of the hangar bay, running parallel to the hangar doors. These primary trusses are approximately $1.0 \mathrm{~m}$ deep and are spaced $7.4 \mathrm{~m}$ on center. The primary trusses are interconnected with a series of secondary trusses which are perpendicular to them and run the length of the hangar bay. The secondary trusses are spaced at intervals ranging from $5.8 \mathrm{~m}$ to 6.4 $\mathrm{m}$ on center. The metal deck roof is directly attached to a series of steel beams which sit on top of the primary and secondary trusses. These steel beams are perpendicular to the primary trusses, are spaced $1.5 \mathrm{~m}$ to $2.1 \mathrm{~m}$ on center, and vary in height from $0.2 \mathrm{~m}$ to $0.3 \mathrm{~m}$.

The roof was insulated via a barrel shaped suspended tile ceiling which was supported by a conventional suspended tile ceiling grid located at the same elevation as the bottom of the steel beams. The individual ceiling tiles in the center bay and the adjacent bay were removed prior to testing.

Experimental east and west were designated to be the directions parallel to the $13.4 \mathrm{~m}$ draft 
curtain and pointed along the direction of the barrel roof. Experimental north and south directions ran perpendicular to the draft curtain. Thermocouples located $0.31 \mathrm{~m}$ beneath the ceiling were at radial distances from fire center of $3.0 \mathrm{~m}, 4.6 \mathrm{~m}, 6.1 \mathrm{~m}$, and $6.7 \mathrm{~m}$ in the south direction and $3.0 \mathrm{~m}$ and $6.1 \mathrm{~m}$ in the north direction. Thermocouples located $0.31 \mathrm{~m}$ beneath the ceiling were at radial distances from fire center of $3.0 \mathrm{~m}, 6.1 \mathrm{~m}, 9.1 \mathrm{~m}, 12.2 \mathrm{~m}, 15.2 \mathrm{~m}$, and 18.3 $\mathrm{m}$. Additional thermocouples were located at many of these locations and are represented in figure 2 .

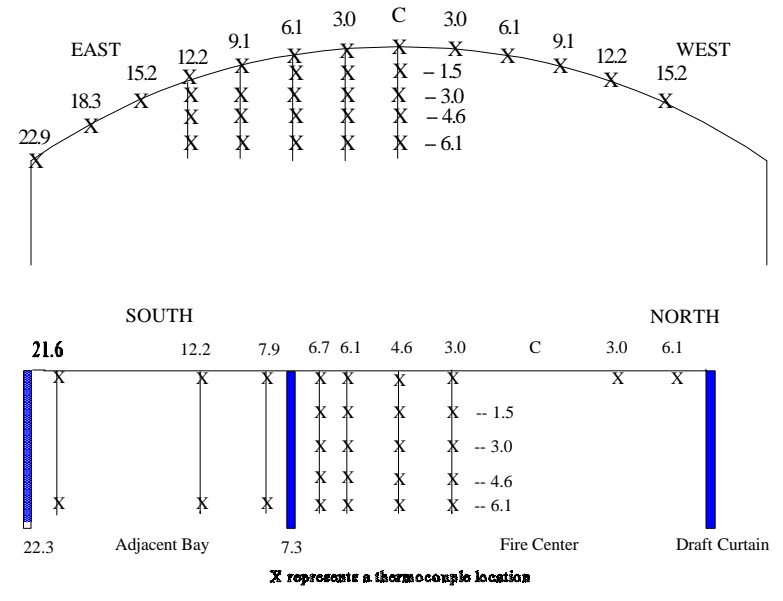

Figure 2 Thermocouple locations ( in $\mathrm{m}$ ) for the hangar at Keflavik.
Twelve of the twenty-one experiments were not included in the analysis due to small fire size or windy conditions within the hangar. Of the remaining nine experiments, two were JP-5 round pan fires of diameters 2.0 $\mathrm{m}$ and $2.5 \mathrm{~m}$ with heat release rates 4.9 MW and 7.9 MW, respectively, while the other seven were square pan fires with sides of $0.9 \mathrm{~m}, 1.2 \mathrm{~m}, 3.0 \mathrm{~m}$, and $4.6 \mathrm{~m}^{1}$. The steady state heat release rates for these fires ranged from 1.4 MW to $33 \mathrm{MW}$. The 14.3 MW fire was a JP-8 square pan fire while all the other fires were JP-5 square pan fires. The heat release rates for all the Keflavik tests except the $33 \mathrm{MW}$ fire test were measured using load cells. The heat release rate for the $33 \mathrm{MW}$ fire was estimated based on pan surface area since the load cell would not support the pan.

\section{PLUME CENTERLINE TEMPERATURE}

The analysis of fire plumes is based on the solution of the conservation laws for mass, momentum and energy. Early work centered on point sources and assumed that the air entrainment velocity at the edge of the plume is proportional to the local vertical plume velocity [5]. Measurements of plume centerline temperature in plumes with unconfined ceilings lead to a correlation developed by Heskestad [6] which qualitatively agreed with theory. The correlation gives the excess temperature as a function of height above a virtual point source to be

${ }^{1}$ Square pan fires were used for UV/IR detector tests to replicate standard industry fire pan sizes. 


$$
\Delta T=9.1\left(\frac{T_{\infty}}{g c_{p}^{2} \rho_{\infty}^{2}}\right)^{1 / 3} Q_{c}^{2 / 3}\left(z-z_{0}\right)^{-5 / 3}
$$

The virtual origin is given by

$$
z_{0}=-1.02 D+0.083 Q^{2 / 5}
$$

where $\mathrm{Q}$ and $\mathrm{Q}_{\mathrm{c}}$ are the total and the convective heat release rates, $\mathrm{D}$ is the pool diameter, $\mathrm{z}$ is the height above the fire surface, and $\mathrm{T}_{\infty}, \mathrm{c}_{\mathrm{p}}$, and $\rho_{\infty}$ are the temperature, heat capacity, and density of the ambient gas. When a hot upper layer forms, this correlation must be modified in order to correctly predict plume centerline temperatures since the plume now includes added enthalpy by entraining hot layer gas as it moves through the upper layer to the ceiling. Methods involving defining a substitute virtual source and heat release rate applicable to the upper layer have been developed by Cooper [7] and Evans [8]. Evans' method is presently used in the computer fire model FPEtool [3]. This method defines the strength $\mathrm{Q}_{\mathrm{I}}$ and location $\mathrm{Z}_{\mathrm{I}}$ of the substitute source by

$$
Q_{I, 2}^{*}=\left[\left(1+C_{T} Q_{I, 1}^{* 2 / 3}\right) / \xi C_{T}-1 / C_{T}\right]^{3 / 2}
$$

and

$$
Z_{I, 2}=\left[\frac{\xi Q_{I, 1}^{*} C_{T}}{Q_{I, 2}^{* 1 / 3}\left[(\xi-1)\left(\beta^{2}+1\right)+\xi C_{T} Q_{I, 2}^{* 2 / 3}\right]}\right]^{2 / 5} Z_{I, 1}
$$

where I refers to the layer interface, 1 and 2 refer to the lower and upper layer, $\xi$ is the ratio of upper to lower layer temperature, $\beta$ is the velocity to temperature ratio of Gaussian profile half widths, and $\mathrm{C}_{\mathrm{T}}=9.115$. The new ceiling height is then obtained from

$$
H_{2}=H_{1}-Z_{I, 1}+Z_{I, 2}
$$

where $\mathrm{Z}_{\mathrm{I}, 1}$ is the height from the fire to the layer interface and $\mathrm{H}_{1}$ is the location of the fire beneath the ceiling. The new values of the fire source and ceiling height are then used in the standard plume correlations where the ambient temperature is now the temperature of the upper 
layer.

\section{RADIATIVE FRACTION}

In order to model fire correctly, the radiative fraction of the heat release rate must be known. For large fires, the radiative fraction $\left(\chi_{\mathrm{r}}\right)$ should decrease as fire size increases due to the increasing absorption path length with respect to the fire center and decreasing surface to volume ratio of the flame. A recent study of the effect of fire size on radiative fraction indicates that this effect may have a substantial impact on the calculation of plume centerline temperatures since as the fire size increases, the radiative fraction decreases allowing for more of the fire energy to heat the plume gases [9]. Of particular interest is the variation of the radiative fraction for kerosene as a function of pan diameter. Based on a series of experiments [10, 11, 12], Yang et al. [9] deduced that the radiative fraction for kerosene remained constant for pan diameters under $0.6 \mathrm{~m}$ but decreased rapidly for pan diameters between $2.0 \mathrm{~m}$ and $40.0 \mathrm{~m}\left(\chi_{\mathrm{r}} \propto \mathrm{D}^{-0.6}\right.$ where $\mathrm{D}$ is the pan diameter). No data were available for pan sizes between $0.6 \mathrm{~m}$ and $2.0 \mathrm{~m}$. The jet fuel JP-5 is close to the composition of kerosene and would be expected to show a similar trend in radiative fraction.

In order to extend this correlation to pan diameters between $1.0 \mathrm{~m}$ and $2.0 \mathrm{~m}$, the output signal from the IR detector portion of the combination UV/IR detectors located $21 \mathrm{~m}$ and $30 \mathrm{~m}$ from fire center divided by HRR was investigated for effective pan diameters between $0.7 \mathrm{~m}$ and $5.2 \mathrm{~m}$.

The IR detector is sensitive to radiation which is emitted in a $0.6 \mu \mathrm{m}$ wide band centered at 4.4 $\mu \mathrm{m}$. The radiative fraction should be proportional to the number of counts/second/HRR provided that the fraction of radiation emitted in this band compared to the total radiation emitted over all wavelengths is independent of pan diameter. For pan diameters between $0.7 \mathrm{~m}$ and $1.5 \mathrm{~m}$, the counts/sec/HRR was proportional to $\mathrm{D}^{-0.7}$ and $\mathrm{D}^{-0.5}$ for the IR detectors at $21 \mathrm{~m}$ and $30 \mathrm{~m}$ respectively. This is in reasonable agreement with the radial dependence found for pan diameters between $2.0 \mathrm{~m}$ and $40.0 \mathrm{~m}$.

The IR counts/second/HRR fell off approximately linearly with pan diameter for the pan fires with diameters between $3.0 \mathrm{~m}$ and $5.2 \mathrm{~m}$. Two reasons may account for this more rapid fall off of radiative fraction with increasing pan diameter. First, if the IR detectors did not see the changing flame height, this would lead to a linear dependence of counts/sec/HRR on pan diameter provided the emitting region resembled a cylindrical flame. The flame heights for the $3.0 \mathrm{~m}$ and $5.2 \mathrm{~m}$ diameter pan fires were observed to extend nearly to the hangar ceiling with intermittent flames being observed at the ceiling for the $5.2 \mathrm{~m}$ pan fire. Second, the fraction of radiation observed by the IR detectors may not be independent of pan diameter for sooty fuels such as JP5. The amount of soot associated with the flame in JP-5 fires increases with pan diameter for pan diameters in excess of $1.0 \mathrm{~m}$. Since soot tends to radiate most strongly at wavelengths shorter than $4.4 \mu \mathrm{m}$, a narrow band detector centered at this wavelength should yield decreasing radiation fractions as the soot concentration increases. Both of these effects may play a role in the observed rapid fall-off in the counts/sec/HRR calculation for the larger pans.

For the calculations performed in the next section, it will be assumed that the fire diameter 
dependence of the radiative fraction of JP-5 is similar to kerosene. The radiative fraction for kerosene is estimated to be

$$
\chi_{r}=0.35 *(2.0 / D)^{0.6}
$$

for pan diameters greater than about $1 \mathrm{~m}$ in diameter.

\section{PLUME CENTERLINE TEMPERATURE COMPARISONS}

Early in the fire experiments, prior to the development of the ceiling layer, the plume centerline temperature should follow the unconfined ceiling correlation. As the ceiling layer develops, the impact of the layer on plume temperature should become evident as hot layer gases are entrained into the plume. Figure 3 shows the plume centerline temperature at approximately $200 \mathrm{~s}$ for eleven experiments. The first two experiments were conducted at Barbers Point and carry a "B" designator, while the remainder were conducted at Keflavik. All experiments used JP-5 except the one designated " 8 " in Keflavik which used JP-8. The total heat release rate is shown for each experiment. Also shown in the figure are the predictions of the plume correlation of Heskestad (Hesk), the plume model of Evans as calculated in version 3.2 of FPEtool (FPEtool), and the prediction of the Evans' model (E-H\&D) in LAVENT.

The Evans' model was implemented as a side calculation in LAVENT. LAVENT was modified such that a user specified radiative fraction as a function of HRR could be input into the program. LAVENT was then used to calculate the upper layer temperature and depth which supplied the necessary inputs for Evans' model, equations 3-5. Evans' model was calculated in a separate subroutine of LAVENT which did not affect either the layer temperture or layer depth calculation. To obtain the plume centerline temperature, the strength and location of the substitute source were put into the correlation of Heskestad and Delichatsios [14] which was evaluated at plume center. The modified version of LAVENT is a test version and is not presently available.

Only the draft curtained area was modeled. This modeling assumption was reasonable early in the tests since both buildings were large enough that it required in excess of $200 \mathrm{~s}$ for the entire ceiling to fill with smoke down to the bottom of the draft curtains. The steady state heat release rate was used in each of the calculations. The radiative fraction was calculated using the correlation given in equation 6 .

The uncertainty intervals shown on the data are one sigma intervals deduced from doing a least squares time average of five data points taken over a twenty second measurement period for the centerline thermocouple located $0.3 \mathrm{~m}$ below the ceiling. These intervals represent the scatter in the measurements which come from a combination of plume sway and fire puffing. A small amount of electronic noise is also included in the intervals. 
No radiation corrections were made to the thermocouple measurements since the smoke surrounding the thermocouples made the environment optically thick. While the absolute uncertainty in thermocouple measurements as reported by the manufacturer is $\pm 2{ }^{\circ} \mathrm{C}$, at the start of each experiment, the thermocouples used in the analysis registered the same ambient temperature to within $1{ }^{\circ} \mathrm{C}$.

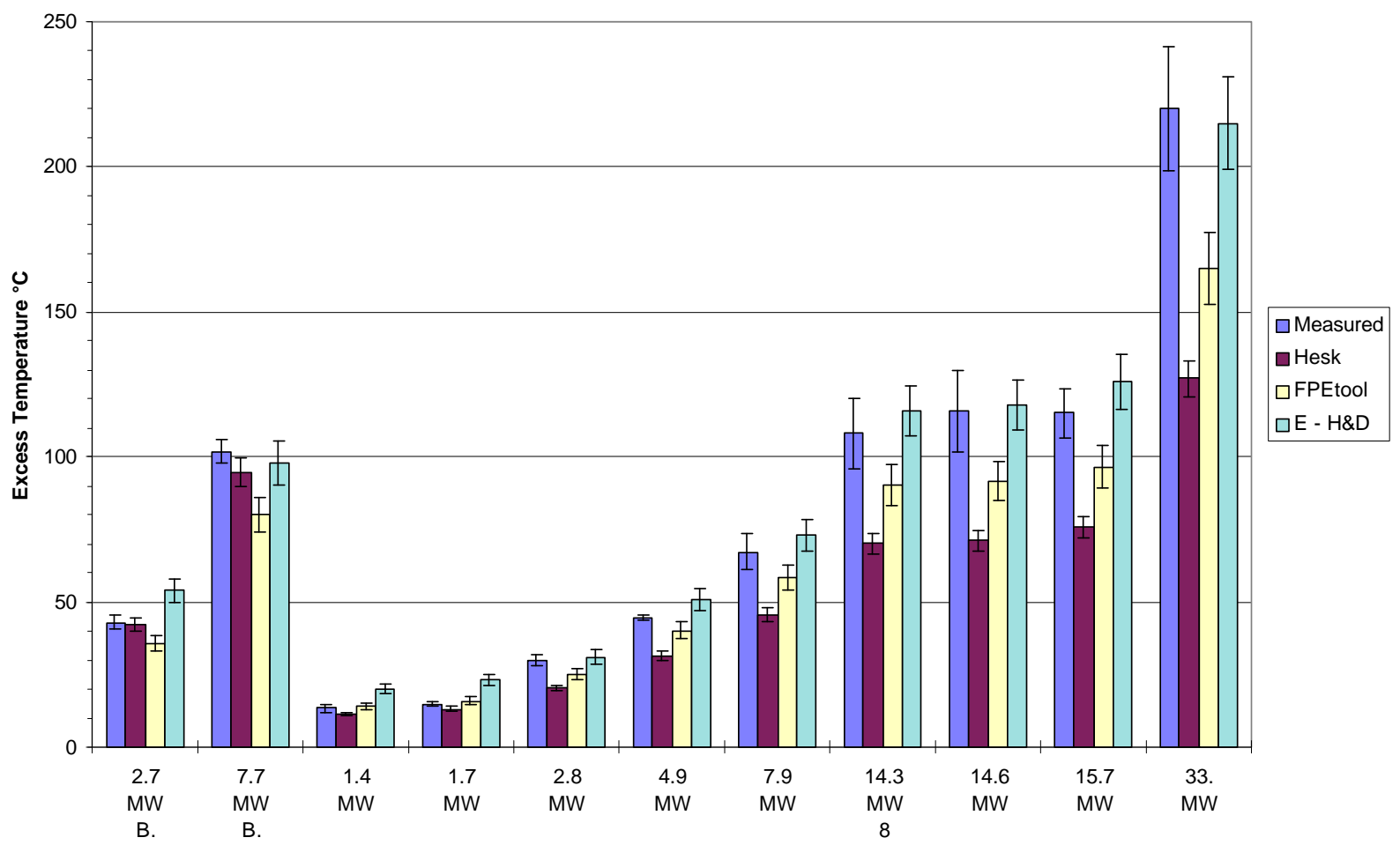

Figure 3 Comparison of Plume Centerline Temperature Excess Models with Experiments. Uncertainty intervals shown for the measured values are one sigma intervals based on a least squares average of five data points taken during a twenty second interval. Uncertainty intervals shown for model temperatures are based on the impact of the estimated uncertainty in the HRR and radiative fraction on the calculated results.

Three of the fire tests conducted at Keflavik were $3.0 \mathrm{~m}$ square pans fires, two JP-5 and one JP-8 fires. These three tests provided an indication of repeatability for the experiments in that the average heat release rates for the three tests were $14.8 \pm 0.7 \mathrm{MW}$ or a repeatability of $\pm 5 \%$. While JP-8 has a lower flash point than JP-5, the cone calorimeter tests for the two fuels indicated

that their heat release rates were identical within the uncertainty of the cone calorimeter [1]. Therefore, the JP- 8 test was included with the JP-5 tests to examine repeatability. 
Measurements that were used in the fire model calculations that would most affect their predictions include the heat release rate and the radiative fraction as a function of pan diameter. The accuracy of the total heat release rate depends on the accuracy of the load cell and of the heat of combustion of the fuel. Uncertainties in the heat release rate were estimated to be approximately $10 \%$ for the fire tests used in this paper [1]. Adding an estimated uncertainty of 5 $\%$ for the uncertainty in radiative fraction, the uncertainty in the convective heat release rate should be $15 \%$. An uncertainty of $15 \%$ in the convective heat release rate would yield an uncertainty of $10 \%$ to $15 \%$ in the temperature predictions of the correlations and computer models used in this paper. The $10 \%$ uncertainty applies to the models with no layer interaction since the excess temperature scales as the convective heat release rate to the $2 / 3$ power. For the models which include a layer interaction, sensitivity studies indicate approximately a $10 \%$ to $15 \%$ uncertainty for an uncertainty of $15 \%$ in the convective heat release rate. The uncertainty intervals shown in figure 3 for the model calculations represent a $\pm 5 \%$ interval for Heskestad's plume theory and $\pm 7.5 \%$ interval for the two computer model calculations.

The plume correlation of Heskestad predicted plume centerline temperatures to within the uncertainty intervals for the 1.4 MW and 1.7 MW fires at Keflavik and the 2.7 MW fire at Barbers Point. The plume centerline temperatures of the larger fires were all underpredicted by this correlation. This was expected as the Heskestad correlation is based on experiments where no layer was allowed to form. Therefore, underprediction of the plume centerline temperature was expected with the best agreement occurring for the smallest fires where only a relatively cool layer would be expected to form.

The method of Evans, as implemented in FPEtool, provided poor agreement with the measurements for the large fires at both Barbers Point and Keflavik. It should be noted that the ambient temperature in FPEtool's Fire Simulator is fixed at $21^{\circ} \mathrm{C}$. Including the proper ambient temperature in Fire Simulator would improve the Barbers Point simulations but increase the discrepancy of the Keflavik simulations. One reason for the underprediction of the plume centerline temperature using FPEtool comes from the way the algorithm is implemented in Fire Simulator. The values for the upper layer fire source and ceiling height, equations 3-5, are put into a correlation developed by Alpert [13]. The temperature computed using this correlation at $\mathrm{r} / \mathrm{H}=0.18$ is the temperature used in FPEtool for all radial positions $\leq 0.18 \mathrm{H}$. This behavior is in conflict with the observations found in these experiments and also in the experimental data set which generated the correlation of Heskestad and Delichatsios [14]. Both of these data sets showed that the plume temperature increased as the distance from plume center decreased with the temperature at $\mathrm{r} / \mathrm{H}=0.18$ being substantially lower than at plume center.

The method of Evans as implemented in LAVENT predicted the plume centerline temperature to within the uncertainties of the measurement for all the large heat release rate experiments but overpredicted the centerline temperature for the smallest heat release rate experiments. One reason for this may be that in Evans' method, a term in the denominator of equation $4,(\xi-1)$, 
approaches zero as the upper layer temperature approaches ambient temperature. The upper layer temperature calculation becomes critical for small fire sizes where the layer temperature is close to ambient.

\section{CEILING JET TEMPERATURE}

The flow of hot plume gas along the ceiling directed radially away from the fire plume is defined as the ceiling jet. The ceiling jet may be represented by temperature and velocity distributions which vary both radially away from the fire center and vertically below the ceiling. The development of a ceiling jet model is complicated by the fact that in an enclosure, a hot gas layer forms near the ceiling which interacts with the ceiling jet.

One of the earliest ceiling jet models was developed by Alpert [13]. This model was based on the ceiling jet flow produced by steady fires for an unconfined ceiling, a ceiling where a gas layer will not form. For $r / H \geq 0.18$, the ceiling jet excess temperature falls off as $r^{2 / 3}$. The temperature is assumed to remain at the value obtained for $\mathrm{r} / \mathrm{H}=0.18$ for $\mathrm{r} / \mathrm{H}<0.18$. This particular correlation is available in the computer programs DETACT-QS [2] and FPEtool [3]. A second steady state ceiling jet correlation developed by Heskestad and Delichatsios [14] gives the excess temperature as

$$
\begin{gathered}
\Delta T=T_{\infty}\left(Q^{*}\right)^{2 / 3} /(0.188+0.313 r / H)^{4 / 3} \\
Q^{*}=Q /\left(\rho_{\infty} C_{p} T_{\infty} g^{1 / 2} H^{5 / 2}\right)
\end{gathered}
$$

When the ceiling jet is confined and a hot layer forms, the presence of the layer must be included in the calculations. Methods of treating the ceiling jet in the presence of a hot layer have been developed by Evans [8] and Cooper [7]. A modified version of Evans' method is presently used in the computer fire model FPEtool while Cooper's method is used in the fire models LAVENT [4] and CFAST [15]. Evans' method uses the strength and location of the substitute source as calculated in equations 3 - 5 which are then substituted in the ceiling jet correlation of Heskestad and Delichatsios. In FPEtool, the ceiling jet correlation of Alpert rather than Heskestad and Delichatsios is used. The layer temperature and layer height needed in the calculations are supplied by a single room zone model in FPEtool.

Cooper's method includes additional phenomena such as modeling the ceiling jet temperature as a function of depth beneath the ceiling and including the possibility that some of the entrained air does not have sufficient buoyancy to enter the upper layer. Also included in the algorithm is a 
radially dependent heat loss calculation to the ceiling. The zone models LAVENT and CFAST use different plume algorithms to calculate the response of the upper layer to the fire; hence the results obtained using this algorithm in the two models may yield somewhat different results.

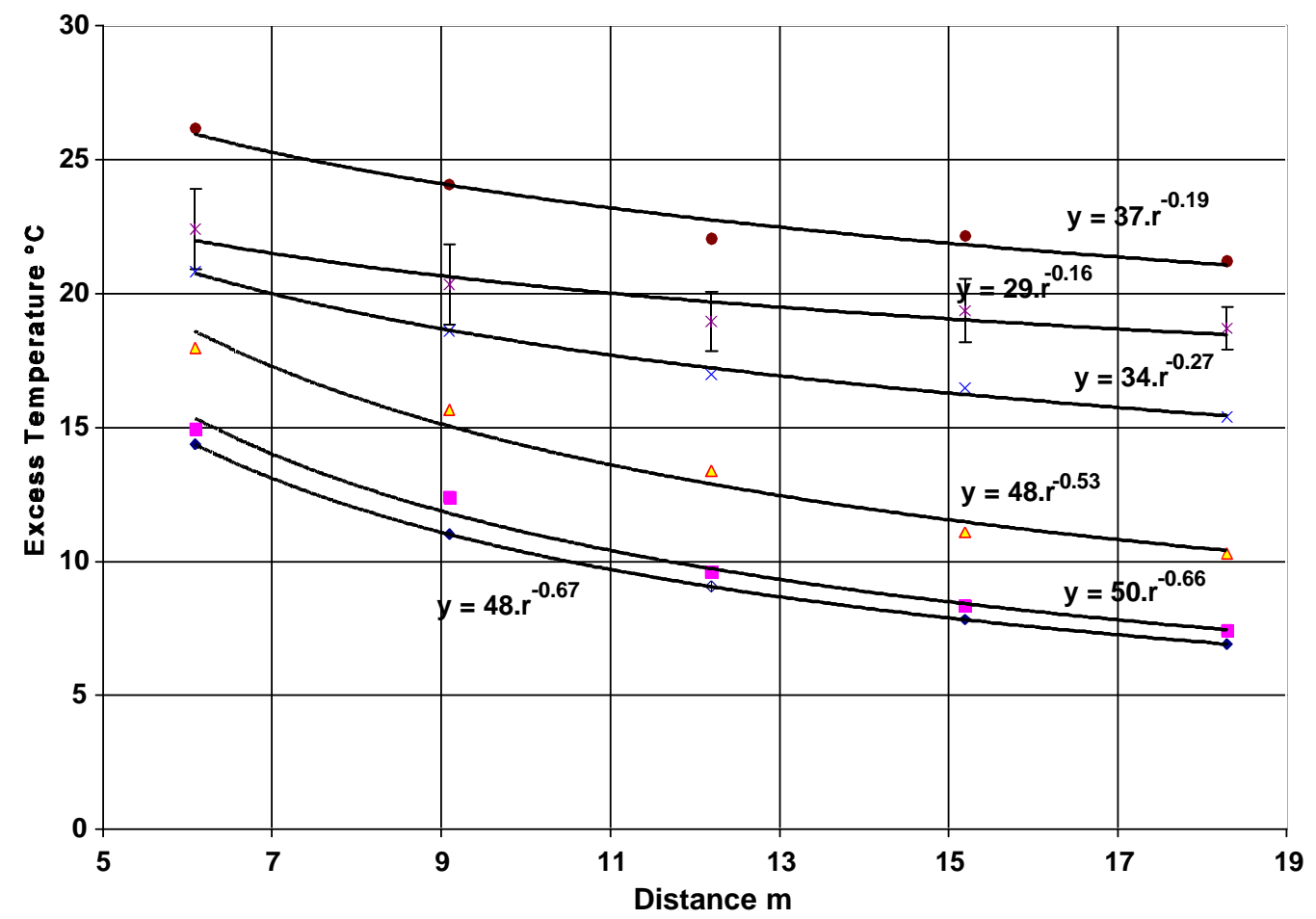

Figure 4 Time evolution of the radial temperature dependence of the ceiling jet for the $2.8 \mathrm{MW}$ JP-5 pan fire at Keflavik. The measurements are averaged on the east and west sides of plume center in the direction of the barrel roof. The lowest curve is Alpert's correlation evaluated using the 2.8 MW heat release rate. The next five curves from bottom to top represent the ceiling jet temperature at times of $80 \mathrm{~s}, 100 \mathrm{~s}, 150 \mathrm{~s}, 200 \mathrm{~s}$, and $300 \mathrm{~s}$. Power law curve fits are given for each data set and Alpert's correlation as a function of distance, $r$, from plume center. Uncertainty intervals shown for the measured values are one sigma intervals based on a least squares average of five data points taken during a twenty second interval.

These models account for the interaction of the plume with the layer resulting in a hotter plume at the ceiling. The models may not account for the presence of the hot gas layer impacting the energy loss of the ceiling jet. The hot gas layer should reduce the radiation loss from the ceiling jet and eliminate the mixing of cool gas into the ceiling jet. The end result should be that the temperature decrease with radial distance should lessen as the ceiling jet becomes more adiabatic. 
This effect has been observed in hood experiments [16].

While the hood experiments were steady state experiments, the high bay experiments allow the ceiling jet temperature dependence to be followed in time. An excellent example of the evolution of the radial temperature dependence of the ceiling jet in time is displayed by the $2.8 \mathrm{MW}$ JP-5 pan fire with draft curtain at Keflavik (Fig. 4). The experimental values are based on an average of five data points centered on the given time with the typical one sigma uncertainty shown on one of the curves. The average time between data points is approximately $4.0 \mathrm{~s}$. Figure 4 shows the temperature evolution in time as well as a comparison to Alpert's ceiling jet correlation. Early in time before a hot layer forms, the temperature dependence of the ceiling jet mirrors Alpert's correlation. The measurements were made in the east direction which is in the direction of the barrel roof. The sloping roof appears not to have produced a significant impact on the ceiling jet temperature until the distance from plume center exceeded $20 \mathrm{~m}$. As the layer formed, the radial dependence of the temperature decreased significantly as the overall

temperature of the jet increased due to the entrainment of the hot layer by the plume. This 
evolution of ceiling jet temperature is evident in all data sets.

Another excellent example would be the 7.7 MW JP-5 pan fire with draft curtain at Barbers Point as shown in figure 5. This ceiling had a negligible slope. Early in time, Alpert's correlation

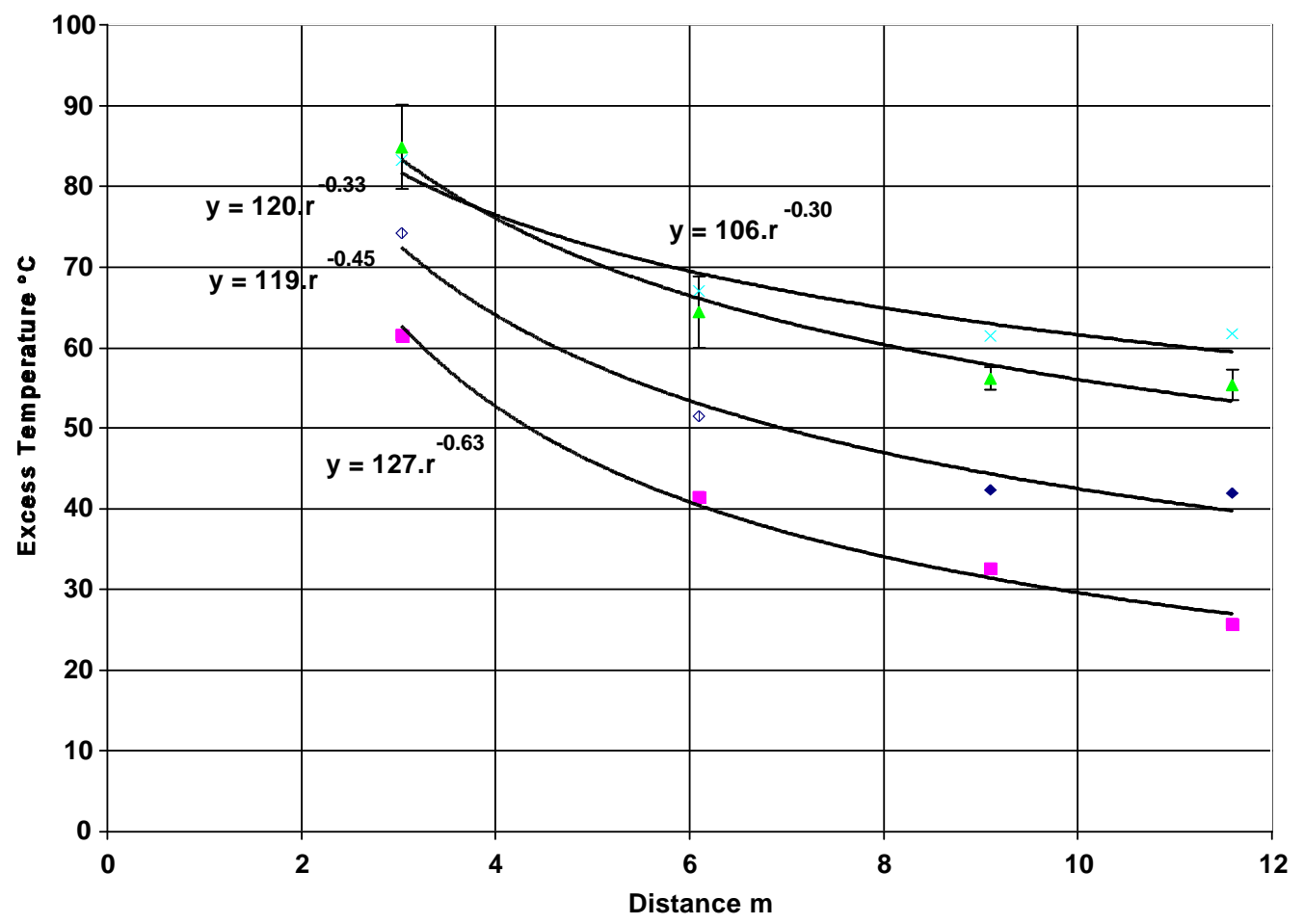

Figure 5 7.7 MW JP-5 pan fire with draft curtain at Barber's Point. The four curves correspond to experimental times of $70 \mathrm{~s}, 100 \mathrm{~s}, 200 \mathrm{~s}$, and $300 \mathrm{~s}$ from bottom to top respectively.

Uncertainty intervals shown for the measured values are one sigma intervals based on a least squares average of five data points taken during a twenty second interval.

$\left(\mathrm{r}^{-0.67}\right)$ would provide a reasonable fit to the radial temperature dependence of the ceiling jet. At later times, the temperature dependence shows a diminished dependence on radial distance from plume center and an increasing overall temperature as the layer depth increases. 
As a final example of the time evolution of the ceiling jet, the 2.8 MW, 4.9 MW, 7.9 MW, 14.6 MW and 15.7 MW JP-5 pan fire tests at Keflavik were scaled to the convective heat release rate of the $2.8 \mathrm{MW}$ test and averaged. The results are presented in figure 6 for an early time before a layer could form and at $200 \mathrm{~s}$ when the layer should fill the draft curtained area. The power law fit for the no layer situation $\left(\mathrm{r}^{-0.73}\right)$ is indistinguishable from Alpert's correlation $\left(\mathrm{r}^{-0.67}\right)$. At later times, the radial dependence of the ceiling jet temperature flattens markedly as the overall

temperature of the ceiling jet increases due to the impact of the layer. The uncertainty intervals shown on the figure represent the one sigma interval deduced from averaging the scaled temperatures at each point from the five tests. In order to include the observed changes in both

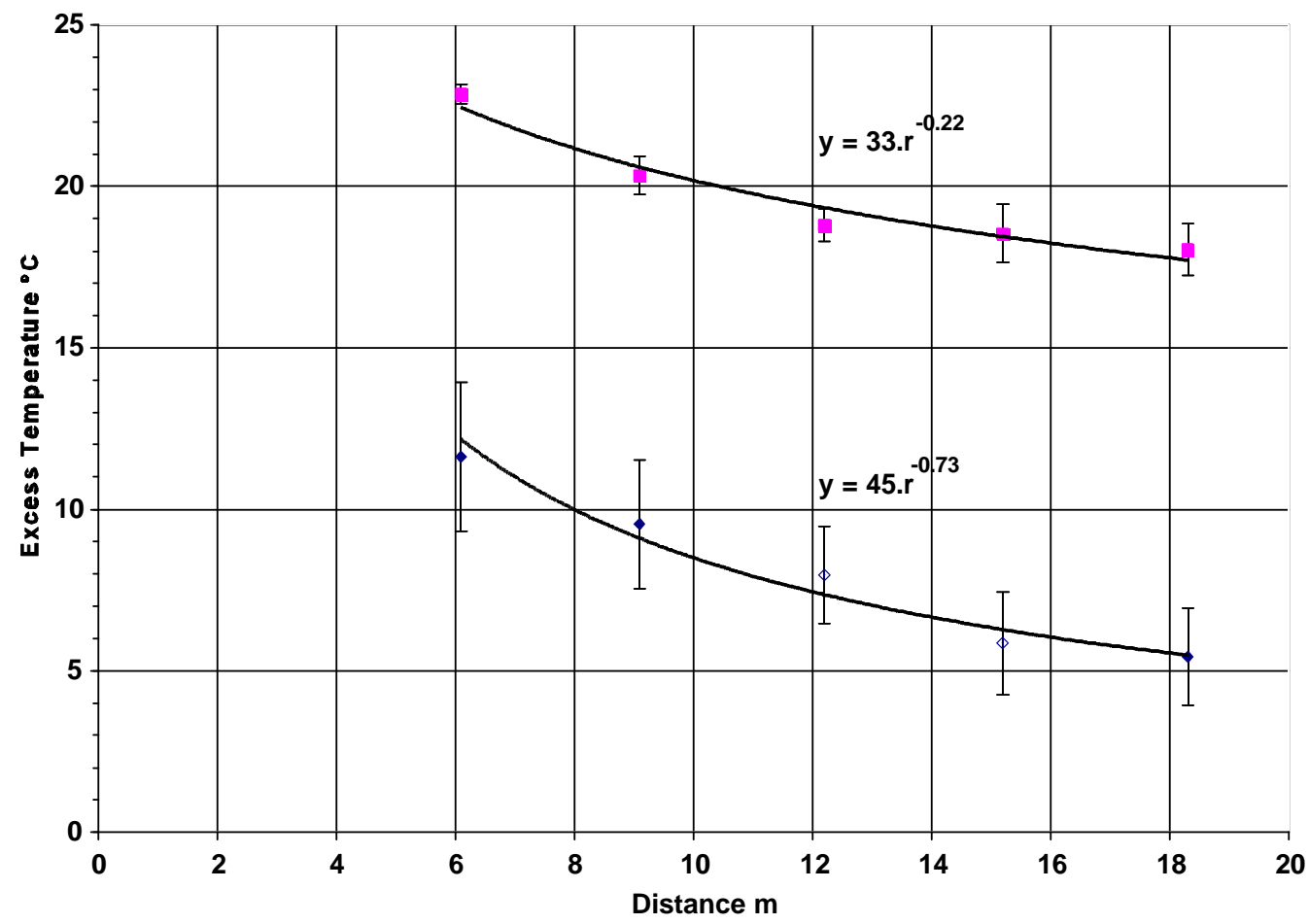

Figure 6 Averaged ceiling jet temperature for the 2.8 MW, 4.9 MW, 7.9 MW, 14.6 MW and 15.7 MW tests at Keflavik. The bottom curve represents the ceiling jet with no layer while the top curve represents the ceiling jet at $200 \mathrm{~s}$ after a layer has filled the draft curtains. Temperatures are scaled to the convective heat release rate of the $2.8 \mathrm{MW}$ test. Uncertainty intervals shown on the figure represent the one sigma interval deduced from averaging the scaled temperatures at each point from the five tests.

the magnitude and radial dependence of the temperature in the ceiling jet, the following 
modification to Alpert's correlation is proposed. The ceiling jet temperature excess $\Delta \mathrm{T}$ as a function of radius for $\mathrm{r} / \mathrm{H}>0.18$ is given by

$$
\Delta T=C / r^{\gamma}
$$

$$
C=k r_{o}^{\gamma} \Delta T_{p}
$$

where

$$
\begin{gathered}
k=\left(0.68+0.16\left(1-e^{-y_{L} y_{J}}\right)\right) \\
r_{o}=0.18 H \\
\gamma=2 / 3-\alpha\left(1-e^{y_{L} y_{J}}\right)
\end{gathered}
$$

and $\alpha=0.44, \mathrm{y}_{\mathrm{J}}=1.0 \mathrm{~m}, \mathrm{y}_{\mathrm{L}}$ is the layer thickness, and $\Delta \mathrm{T}_{\mathrm{p}}$ is the plume centerline temperature excess as calculated using Evans' method (equations 3-5 \& 7-8). The value of $\alpha$ is determined by the requirement that with no hot layer, the radial dependence on the ceiling jet temperature should follow Alpert's value of $2 / 3$ while after the layer forms, the radial dependence will be reduced to a 
minimum of 0.23 as the layer depth increases. The experimental value for this parameter is $0.23 \pm$ 0.07 . The value of $\mathrm{k}$ (maximum value equals 0.84 ) is based on the experimentally observed decrease in temperature difference between the plume centerline temperature and the ceiling jet temperature at $\mathrm{r} / \mathrm{H}=0.18$ as the hot layer depth increases in time. Early in time, before a layer forms, the experimentally determined value of $\mathrm{k}$ is $0.67 \pm .11$ while once a layer forms, the value increases to $0.84 \pm 0.04$. This increase is caused by the decrease in the entrainment of cool gas into the ceiling jet due both to the presence of the hot layer and to the circulation of ceiling jet flow back into the plume by the draft curtains. The value of $y_{j}$ was chosen to be 1.0 based on the

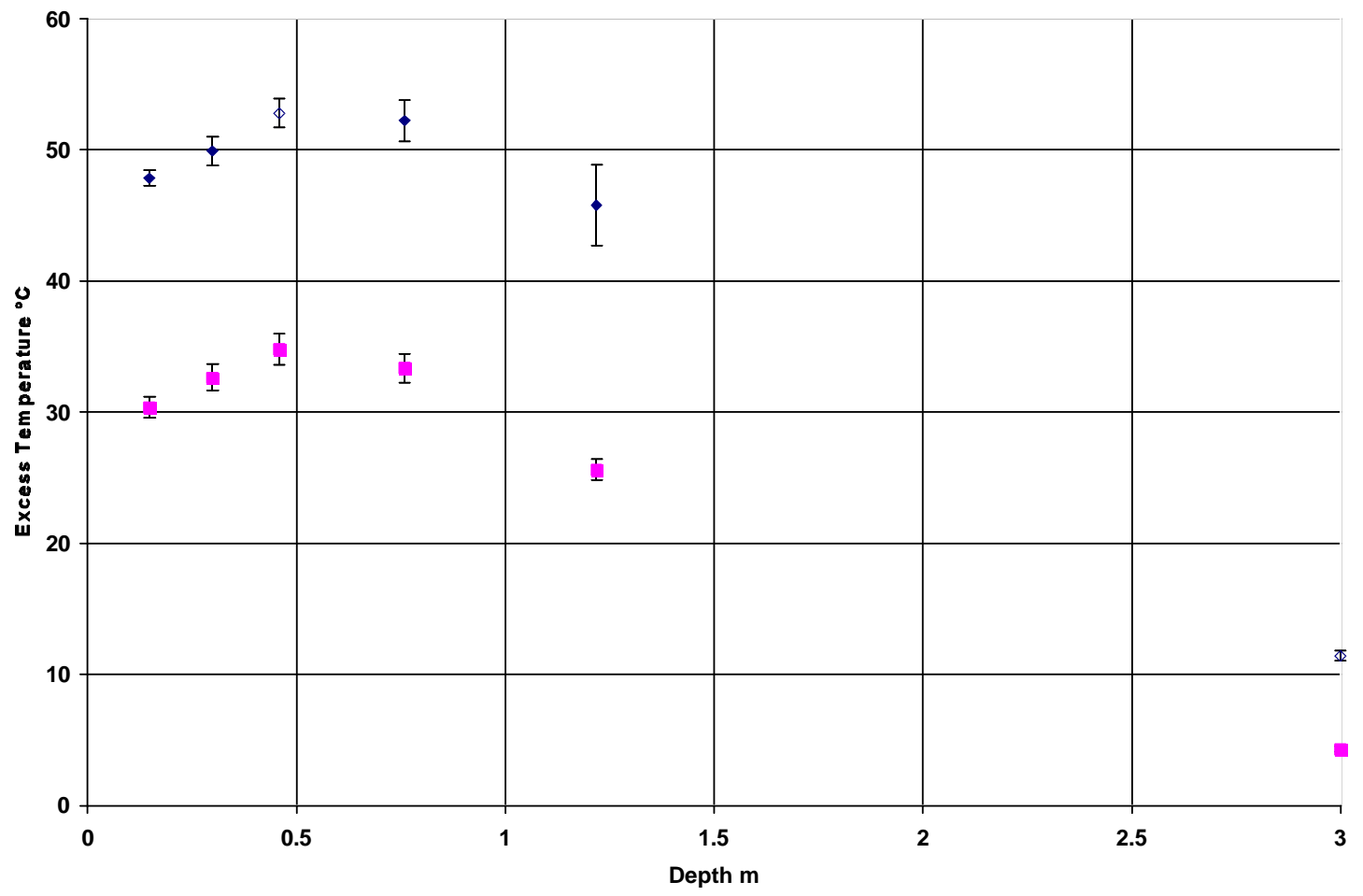

Figure 7 Excess temperature as a function of depth for the 7.7 MW JP-5 pan fire without draft curtain at Barbers Point. The squares and diamonds represent experiment times after ignition of $100 \mathrm{~s}$ and $400 \mathrm{~s}$ respectively. Uncertainty intervals shown for the measured values are one sigma intervals based on a least squares average of five data points taken during a twenty second interval.

observation that JP-5 plumes become optically thick at a diameter of approximately $1.0 \mathrm{~m}$, thereby eliminating the energy loss by radiation once the layer has reached this thickness. 


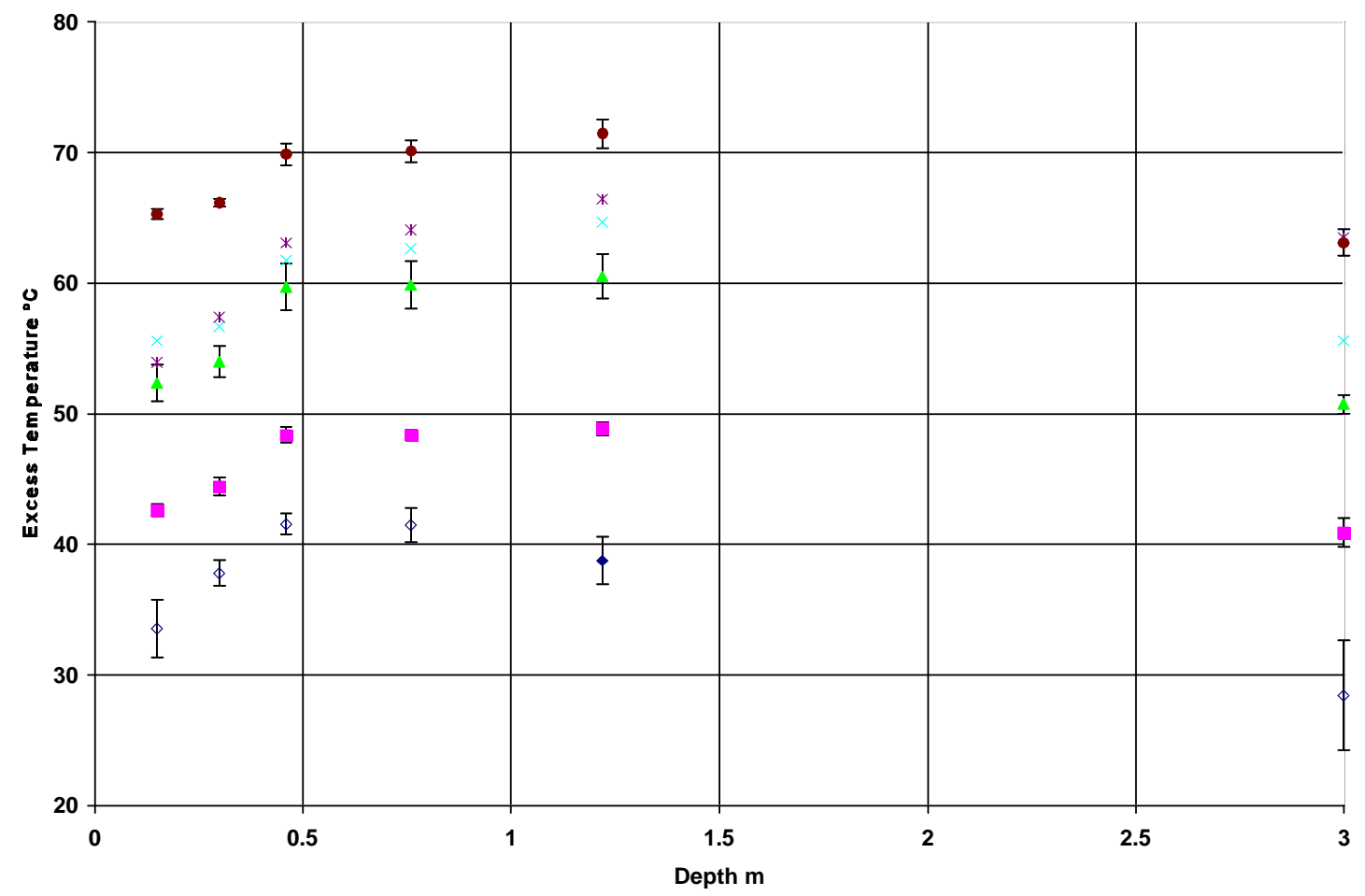

Figure 8 Excess temperature as a function of depth for the 7.7 MW JP-5 pan fire with draft curtain at Barbers Point. The curves shown on the graph represent measurement times of $70 \mathrm{~s}$, $100 \mathrm{~s}, 150 \mathrm{~s}, 200 \mathrm{~s}, 250 \mathrm{~s}$, and $300 \mathrm{~s}$ from bottom to top respectively. Uncertainty intervals shown for the measured values are one sigma intervals based on a least squares average of five data points taken during a twenty second interval.

The temperature dependence as a function of distance below the ceiling must be understood as the proposed ceiling jet model makes no accommodation for temperature changes with depth. Three experiments conducted at Keflavik plus the experiments conducted at Barbers Point had sufficient numbers of thermocouples in the vertical direction to resolve the vertical temperature structure near the ceiling. For the two experiments without draft curtains at Barbers Point (see figure 7 for the 7.7 MW fire without draft curtains at Barbers Point), the ceiling jet temperature reached a maximum value at roughly $0.5 \mathrm{~m}$ below the ceiling at which point a fairly rapid decline occurred, with the excess temperature being nearly zero at a depth of $3.1 \mathrm{~m}$ beneath the ceiling. From the data, the thickness of the ceiling jet for these experiments would range from $2.0 \mathrm{~m}$ to $3.0 \mathrm{~m}$ which is 14 percent to 21 percent times the fire to ceiling height distance. This is slightly thicker than the 5 percent to 12 percent of the fire to ceiling height suggested in [13].

The maximum temperature was reached at about 3 percent of the fire to ceiling height which is 


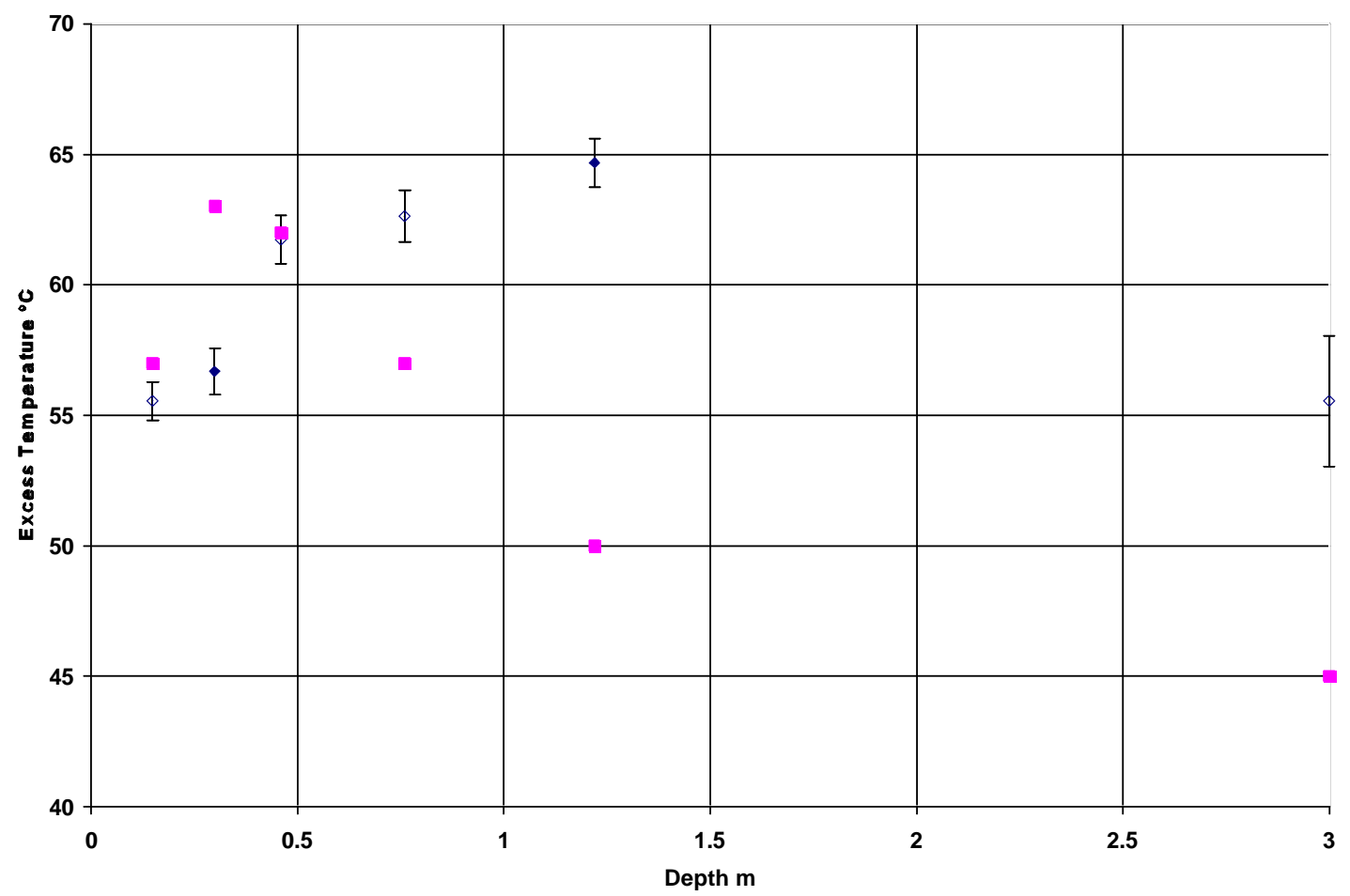

Figure 9 Comparison of the measured ceiling jet temperature profile at $r=9.1 \mathrm{~m}$ for the $7.7 \mathrm{MW}$ JP-5 pan fire with a draft curtain. The diamonds represent the data at $200 \mathrm{~s}$ while the squares give the predictions of LAVENT. The excess temperature is uncertain by $\pm 7.5 \%$ but the shape of the temperature profile will not be affected by this uncertainty. Uncertainty intervals shown for the measured values are one sigma intervals based on a least squares average of five data points taken during a twenty second interval.

larger than the 1 percent value given in reference [13]. It should be noted that the difference in the position of the maximum temperature may be due to the presence of the ceiling I-beams of depth $0.25 \mathrm{~m}$.

Once the layer forms, the temperature still reaches a maximum at roughly $0.5 \mathrm{~m}$ beneath the ceiling. The temperature remains at approximately this maximum value for a substantial depth beneath the ceiling. A good demonstration of this behavior is shown in figure 8 for the $7.7 \mathrm{MW}$ fire with draft curtain at Barbers Point. Uncertainty intervals are not shown for two data sets in this figure in order to avoid cluttering the figure but the uncertainty intervals will be approximately the same as the ones shown in the figure. The thermocouple tree was located at $9.1 \mathrm{~m}$ east of fire center. At $70 \mathrm{~s}$ after the start of the fire, the maximum temperature of the ceiling jet is located at roughly $0.5 \mathrm{~m}$ beneath the ceiling. The temperature of the jet begins to 
decrease at about $1 \mathrm{~m}$ beneath the ceiling. At later times after a layer has formed, the temperature still rises rapidly for the first $0.5 \mathrm{~m}$ beneath the ceiling. It then remains either constant or rises slightly for the next $0.75 \mathrm{~m}$. The depth at which the temperature begins to decline when a layer is present cannot be determined with the present data set.

A comparison of the temperature profile of the ceiling jet for the 7.7 MW fire with draft curtain at Barbers Point with the profile predicted by LAVENT is shown in figure 9. The ceiling jet model in LAVENT predicts the temperature maximum closer to the ceiling than observed and yields a ceiling jet temperature profile which is substantially more narrow than observed. Comparing the predictions of LAVENT with the 7.7 MW fire without a draft curtain at Barbers Point (figure 10), the position of the maximum temperature point in the ceiling jet is again closer to the ceiling then measured but the shape of the ceiling jet profile is much closer to the measured profile.

While the temperatures predicted by LAVENT depend on the convective heat release rate, the

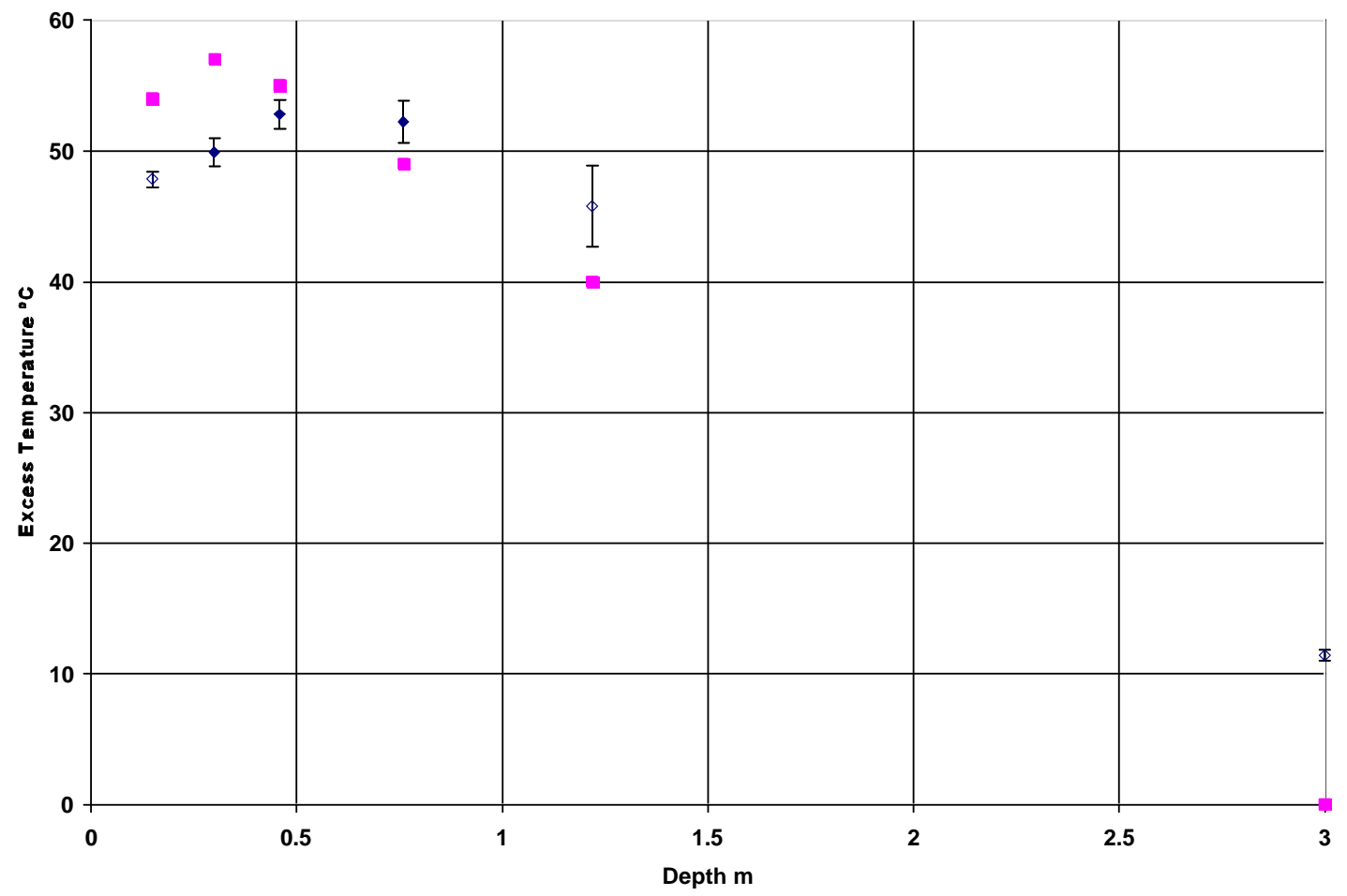

Figure 10 Comparison of the measured ceiling jet temperature profile at $\mathrm{r}=9.1 \mathrm{~m}$ for the 7.7 MW JP-5 pan fire without a draft curtain. The diamonds represent the data at $400 \mathrm{~s}$ while the squares give the predictions of LAVENT. Uncertainty intervals shown for the measured values are one sigma intervals based on a least squares average of five data points taken during a twenty second interval. 
shape of the profile is independent of the HRR. Therefore, while the temperatures calculated using LAVENT are uncertain by $\pm 7.5 \%$, the position of the temperature maximum will not change due to this uncertainty.

The presence of the layer increases the depth over which the high temperatures persist near the ceiling. Since in both situations, with and without a layer, the high temperature region was at least $0.5 \mathrm{~m}$ in depth, the need to model the temperature fall off with depth beneath the ceiling is probably not important. The important issue is to establish the distance that the maximum temperature is reached beneath the ceiling since positioning sprinklers too close to the ceiling will delay or prevent their activation.

The models FPEtool, LAVENT, and the proposed ceiling jet model (equations 9 - 13) are compared with the measured temperature $0.3 \mathrm{~m}$ beneath the ceiling at $200 \mathrm{~s}$ for the $14.6 \mathrm{MW}$ test at Keflavik (figure 11). The proposed ceiling jet model used the layer temperature and height predictive capabilities of LAVENT version 1.2 which resulted in a new computational model designated JET. The models are compared with the averaged east-west data taken along the sloping barrel roof. Total temperature is used since FPEtool can only be run with an ambient temperature of $21^{\circ} \mathrm{C}$. The other two models used the measured ambient temperature of $14{ }^{\circ} \mathrm{C}$. The radiative fraction used in the calculation for JET and FPEtool was calculated from equation 9. LAVENT uses a fixed radiative fraction of 0.35 which is too high based on the earlier discussion of radiative fraction. Decreasing the radiative fraction for the LAVENT calculation would increase both the layer and ceiling jet temperature predictions. 


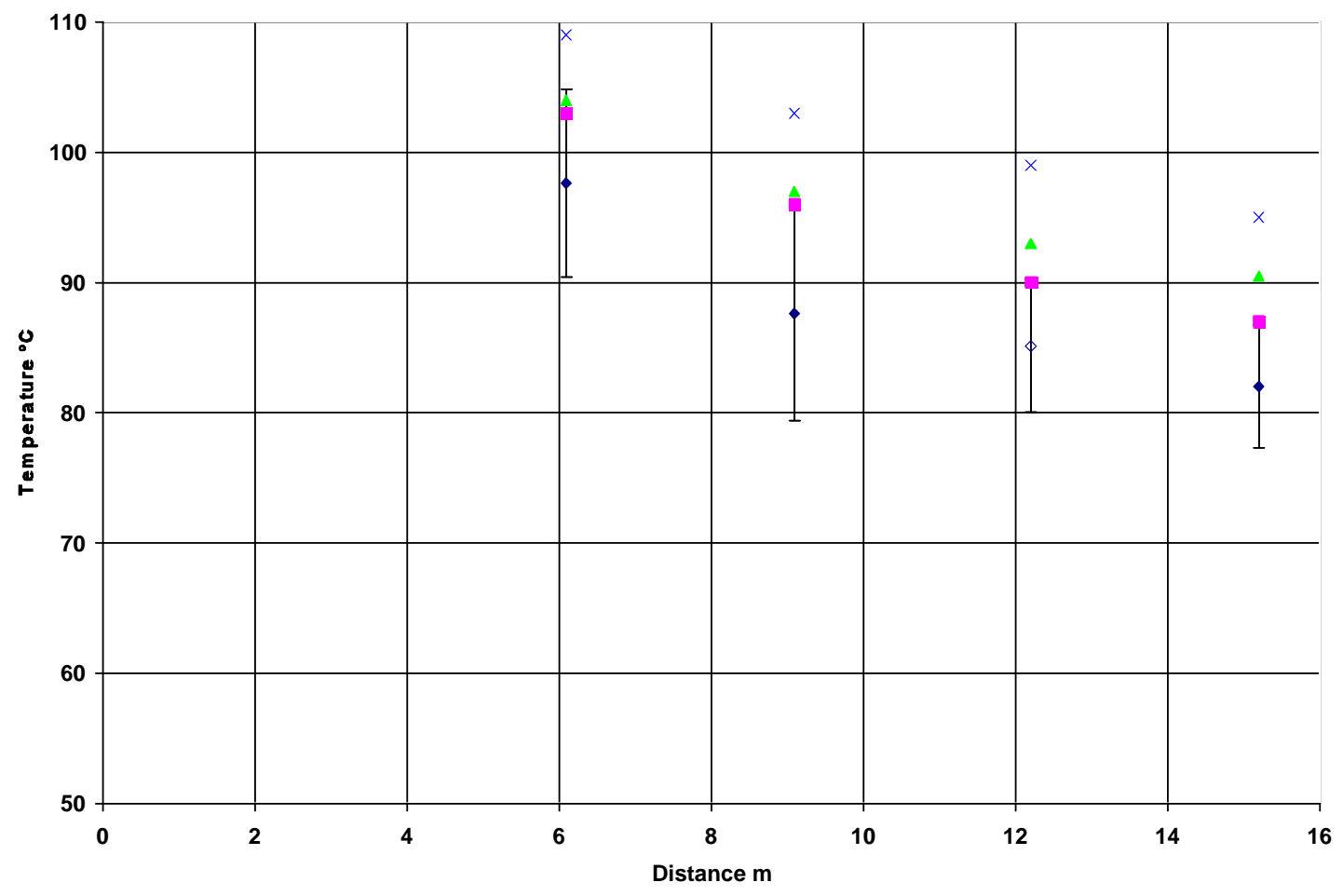

Figure 11 Comparison of ceiling jet temperature predictions of the models FPEtool (triangles), LAVENT (x), and JET (squares) with the measured values (diamonds) at $200 \mathrm{~s}$ for the $14.6 \mathrm{MW}$ experiment at Keflavik. Uncertainty in the convective heat release rate will yield an uncertainty of $\pm 6^{\circ} \mathrm{C}$ in the temperature predictions of the computer models but will not affect the radial temperature dependence. Uncertainty intervals shown for the measured values are one sigma intervals based on a least squares average of five data points taken during a twenty second interval.

All three models overpredict the measured ceiling jet temperature although JET and FPEtool provide predictions which would lie inside the combined measurement uncertainty for the convective heat release rate and the experiment. All three models display a similar radial dependence with temperature which is similar to that measured in the experiment. 


\section{CONCLUSION}

Based on the comparisons of the model predictions of DETACT-QS, FPEtool version 3.2, LAVENT version 1.2, and JET, the following conclusions may be drawn.

1. The correlations of Alpert and Heskestad gave predictions which agreed with the measurements when hot layers did not form. Once a hot layer formed, these correlations substantially underpredicted plume centerline temperature and ceiling jet temperature. In typical compartment fires with limited ventilation, models based on these correlations may yield unacceptable results.

2. As presently configured, the fire simulator portion of FPEtool will underpredict the plume centerline temperature. The fire simulator portion of FPEtool does attempt to account for the presence of a layer by using Evans' method when the layer exceeds a thickness equal to 0.12 of the fire to ceiling height but assumes that the plume temperature will be constant for distances inside $\mathrm{r} / \mathrm{H}=0.18$. The radial dependence of the ceiling jet temperature is computed using Alpert's correlation which overpredicts the ceiling jet temperature decrease with distance from plume center when a hot layer is present.

3. The importance of including both the entrainment of upper layer gases and a radiative fraction which is a function of fire diameter has been demonstrated in the predictions of the plume centerline temperature. Excluding either effect will cause fire models to underpredict the plume centerline temperature for large fires.

4. An algorithm for calculating ceiling jet temperature has been designed to simulate the observed layer dependent temperature variation of the ceiling jet to the growing layer. This algorithm needs to be verified using additional experimental data. In particular, the question of whether the layer dependent behavior observed for the ceiling jet temperature in these experiments will be reproduced with less smokey fuels should be investigated. A partial answer to this question is already available based on the experimental work of Motevalli and Ricciuti [17] who used a $1.0 \mathrm{~m}$ high enclosure and a methane burner to study the dynamics of the confined and unconfined ceiling jet. Their results support the layer dependent behavior of the ceiling jet reported in this analysis. 


\section{REFERENCES}

1. Gott, J. E., Lowe, D. L., Notarianni, K. A., and Davis W. D., “Analysis of High Bay Hangar Facilities for Fire Detector Sensitivity and Placement.," National Institute of Standards and Technology, NIST TN 1423, 1997, pp. 1-315.

2. Evans, D. D., and Stroup, D. W., "Methods to Calculate the Response Time of Heat and Smoke Detectors Installed Below Large Unobstructed Ceilings," Fire Tech., 22, 1986, pp. 54-63.

3. Deal, S., “Technical Reference Guide for FPEtool, Version 3.2," National Institute of Standards and Technology, NISTIR 5486-1, 1995, pp. 1-127.

4. Davis, W. D., and Cooper, L. Y., "Estimating the Environment and the Response of Sprinkler Links in Compartment Fires with Draft Curtains and Fusible Link-Actuated Ceiling Vents - Part II: User Guide for the Computer Code LAVENT," National Institute of Standards and Technology, NISTIR 89-4122, 1989, pp. 1-36.

5. Morton, B. R., Taylor, B. I., and Turner, J. S., "Turbulent Gravitational Convection from Maintained and Instantaneous Sources," Proc. Roy. Soc. A234, 1956, pp. 1-23.

6. Heskestad, G., "Engineering Relations for Fire Plumes," Fire Safety J., 7 1984, pp. 25-32.

7. Cooper, L. Y., "Estimating the Environment and the Response of Sprinkler Links in Compartment Fires with Draft Curtains and Fusible Link-Actuated Ceiling Vents - Part I: Theory," National Institute of Standards and Technology, NBSIR 88-3734, 1988, pp. 132.

8. Evans, D. D., "Calculating Sprinkler Actuation Time in Compartments," F. Safety J., 9, 1985, pp. 147-155.

9. Yang, J. C., Hamins, A., and Kashiwagi, T., "Estimate of the Effect of Scale on Radiative Heat Loss Fraction and Combustion Efficiency," Combustion Science and Technology, 96, 1994, pp. 183-188.

10. Souil, J. M., Vantelon, J. P., Joulain, P., and Grosshandler, W. L. "Experimental and Theoretical Study of Thermal Radiation from Freely Burning Kerosene Pool Fires," Progress in Astronautics \& Aeronautics (J. R. Bowen, J.-L. Leyer, and R. I. Solenkhin, Eds.), AIAA Vol. 105, 1986, pp. 388-401.

11. Koseki, H. And Yumoto, T. "Air Entrainment and Thermal Radiation from Heptane Pool Fires,” Fire Technology, 24, 1988, pp 33-47. 
12. Koseki, H., "Combustion Properties of Large Liquid Pool Fires," Fire Technology, 25, 1989, pp 241-255.

13. Alpert, R. L., "Calculation of Response Time of Ceiling-Mounted Fire Detectors," Fire Technology, 8, 1972, pp. 181-195.

14. Heskestad, G., and Delichatsios, M. A., “The Initial Convective Flow in Fire," 17th International Symposium on Combustion, Combustion Institute, Pittsburgh , 1978, pp. 1113-1123.

15. Peacock, R. D., Forney, G. P., Reneke, P., Portier, R., and Jones, W. W., "CFAST, the Consolidated Model of Fire Growth and Smoke Transport," National Institute of Standards and Technology, NIST TN 1299, 1993, pp. 1-235.

16. Zukowski, E. E., and Kubota, T., "An Experimental Investigation of the Heat Transfer from a Buoyant Gas Plume to a Horizontal Ceiling, Part II. Effects of Ceiling Layer," National Institute of Standards and Technology, NBS-GCR-77-98, 1975, pp. 1-73.

17. Motevalli, V., and Ricciuti, C., "Characterization of the Confined Ceiling Jet in the Presence of an Upper Layer in Transient and Steady-State Conditions," National Institute of Standards and Technology, NIST-GCR-92-613, 1992, pp. 1-134. 